\title{
Caspase-mediated cleavage of Beclin-1 inactivates Beclin-1-induced autophagy and enhances apoptosis by promoting the release of proapoptotic factors from mitochondria
}

\author{
E Wirawan $^{1,2}$, L Vande Walle ${ }^{1,2,5}$, K Kersse $^{1,2,5}$, S Cornelis ${ }^{1,2,6}$, S Claerhout ${ }^{3}$, I Vanoverberghe ${ }^{1,2}$, R Roelandt ${ }^{1,2}$, R De Rycke ${ }^{2,4}$, \\ J Verspurten $^{1,2}$, W Declercq ${ }^{1,2}$, P Agostinis ${ }^{3}$, T Vanden Berghe ${ }^{1,2}$, S Lippens ${ }^{1,2,7}$ and P Vandenabeele ${ }^{\star, 1,2,7}$
}

Autophagy and apoptosis are two important and interconnected stress-response mechanisms. However, the molecular interplay between these two pathways is not fully understood. To study the fate and function of autophagic proteins at the onset of apoptosis, we used a cellular model system in which autophagy precedes apoptosis. IL-3 depletion of $\mathrm{Ba} / \mathrm{F} 3$ cells caused caspase (casp)-mediated cleavage of Beclin-1 and PI3KC3, two crucial components of the autophagy-inducing complex. We identified two casp cleavage sites in Beclin-1, TDVD ${ }^{133}$ and DQLD ${ }^{149}$, cleavage at which yields fragments lacking the autophagyinducing capacity. Noteworthy, the C-terminal fragment, Beclin-1-C, localized predominantly at the mitochondria and sensitized the cells to apoptosis. Moreover, on isolated mitochondria, recombinant Beclin-1-C was able to induce the release of proapoptotic factors. These findings point to a mechanism by which casp-dependent generation of Beclin-1-C creates an amplifying loop enhancing apoptosis upon growth factor withdrawal.

Cell Death and Disease (2010) 1, e18; doi:10.1038/cddis.2009.16; published online 21 January 2010

Subject Category: Cancer

This is an open-access article distributed under the terms of the Creative Commons Attribution License, which permits distribution and reproduction in any medium, provided the original author and source are credited. This license does not permit commercial exploitation without specific permission.

Under favorable conditions, cells maintain a balance between synthesis, degradation and recycling of cellular components. One key regulatory mechanism maintaining this balance is autophagy, a catabolic process involving engulfment of proteins, lipids and/or organelles by double-membrane vesicles, the autophagosomes, and consequent breakdown of these components after fusion with lysosomes. Under stress conditions, such as growth factor deprivation, autophagy increases in order to provide the nutrients needed for metabolism. Autophagy is tightly regulated by a group of evolutionarily conserved genes, the atg (autophagy-related) genes. ${ }^{1}$ A key protein in autophagy signaling is Bcl-2interacting protein-1 (Beclin-1), the mammalian homolog of yeast Atg6. ${ }^{2}$ Beclin-1 functions as a platform by binding to phosphatidylinositol-3-kinase class-3 (PI3KC3)/vacuolar protein sorting-34 (Vps34), UV-resistance-associated gene (UVRAG), AMBRA-1 (activating molecule in Beclin-1-regulated autophagy) and/or Barkor (Beclin-1-associated autophagyrelated key regulator) to assemble the $\mathrm{PI} 3 \mathrm{KC} 3$ complex during initiation of autophagosome formation. ${ }^{3-7}$ The autophagic response of embryonic stem (ES) cells deficient in Beclin-1 is severely altered. Absence of both Beclin-1 alleles in mice leads to embryonic death, demonstrating the importance of autophagy in the maintenance of tissue homeostasis. ${ }^{8,9}$

Cellular stress may also result in cell death. Apoptosis, as a prototype of cell death, is induced either via the extrinsic

\footnotetext{
${ }^{1}$ VIB, Department for Molecular Biomedical Research, Unit for Molecular Signalling and Cell Death, Technologiepark 927, Ghent B-9052, Belgium; ${ }^{2}$ Department of Biomedical Molecular Biology, Unit for Molecular Signalling and Cell Death, Ghent University, Technologiepark 927, Ghent B-9052, Belgium; ${ }^{3}$ KULeuven, Laboratory for Cell Death and Therapy, Department for Molecular and Cell Biology, O\&N I Herestraat 49, Leuven B-3000, Belgium and ${ }^{4}$ Microscopy Core Facility, Department for Molecular Biomedical Research, VIB - Ghent University, Ghent, Belgium

*Corresponding author: P Vandenabeele, Ghent University, Technologiepark 927, Ghent (Zwijnaarde) B-9052, Belgium. Tel: + 3293313763 ; Fax: + 3293313609 ; E-mail: peter.vandenabeele@dmbr.vib-Ugent.be

${ }^{5}$ These authors contributed equally to this work.

${ }^{6}$ Current address: Ablynx, NV Technologiepark 4, Zwijnaarde B-9052, Belgium

${ }^{7}$ These authors share senior authorship.

Keywords: autophagy; Beclin-1; PI3KC3; apoptosis; caspases; Ba/F3; IL-3

Abbreviations: AMBRA-1, activating molecule in Beclin-1-regulated autophagy; Atg, autophagy-related gene; Barkor, Beclin-1-associated autophagy-related key regulator; Bcl-2, B-cell lymphoma-2; Bcl-XL, B-cell lymphoma extra long; Beclin-1, Bcl-2-interacting protein-1; BH3, Bcl-2 homology domain-3; casp, caspase; cyt c, cytochrome $c$; ES cells, embryonic stem cells; FL, full length; HtrA2, high-temperature requirement protein-A2; IL-3, interleukin-3; LC3, microtubule-associated protein light chain-3; PARP, poly-ADP (adenosine diphosphate)-ribose polymerase; PI, propidium iodide; PI3KC3, phosphatidylinositol-3-kinase class-3; TEM, transmission electron microscopy; TRAIL, tumor necrosis factor-related apoptosis-inducing ligand; UVRAG, UV-resistance-associated gene; Vps34, vacuolar protein sorting-34; zVAD-fmk, carbobenzoxy-valyl-analyl-aspartyl-[0-methyl]-fluoromethylketone

Received 27.11.09; accepted 27.11.09; Edited by Gerry Melino
} 
pathway by death-receptor triggering, or via the intrinsic pathway when mitochondrial pro-death factors, such as cytochrome c (cyt $c$ ) and HtrA2 (high-temperature requirement protein-A2)/Omi, are released. ${ }^{10}$ Apoptotic signaling leads to activation of caspases (casps), ${ }^{11-13}$ which specifically cleave native proteome substrates after aspartate residues, resulting in delocalization of proteins, loss or gain of function, or loss of complex formation. ${ }^{14}$ Cleavage of these substrates during apoptosis leads to the typical biochemical and morphological characteristics, such as chromatin condensation, DNA fragmentation, cell shrinkage, and membrane blebbing. ${ }^{15,16}$ While apoptosis is clearly a primary cell death mechanism, there is much controversy about the functional role of autophagy in life and death. ${ }^{17,18}$ Depending on the cellular context, the cell line and the stimulus, autophagy either favors or counteracts cell death signaling. ${ }^{19-21}$ It is believed that multiple connections exist between autophagy and apoptosis, and so the molecular interplay and functional relationship between their pathways have gained considerable interest. ${ }^{22-24}$

Beclin-1 was recently identified as a novel $\mathrm{Bcl}-2$ homology domain-3 (BH3)-only member of the B-cell lymphoma-2 (Bcl2) family; it possesses a Bcl-2 homology-3 $(\mathrm{BH} 3)$ domain that mediates its interaction with the antiapoptotic proteins $\mathrm{Bcl}-2$ and $\mathrm{Bcl}-\mathrm{x}_{\mathrm{L}}$ (B-cell lymphoma extra long). ${ }^{25-27}$ Binding of Beclin-1 to $\mathrm{Bcl}-2$ or $\mathrm{Bcl}-\mathrm{x}_{\mathrm{L}}$ inhibits the autophagic function of Beclin-1, ${ }^{26,28}$ suggesting that Beclin-1 might have a role in the convergence between autophagy and apoptotic cell death. In this study we aimed to investigate the crosstalk between these pathways and explore the fate of the autophagy proteins Beclin-1 and PI3KC3 during apoptosis. We used a cellular model system in which growth factor deprivation induces autophagy followed by apoptotic cell death. Our data clearly demonstrate the interplay between autophagy and apoptosis, as casp-mediated cleavage not only abrogates the autophagic function of Beclin-1, but also generates a Beclin-1-C fragment that can enhance the apoptotic pathway. By using purified Beclin-1-C fragments we showed that Beclin-1-C can release cyt $c$ and $\mathrm{HtrA2/Omi} \mathrm{from} \mathrm{mitochondria.}$

\section{Results}

Autophagy precedes apoptosis induced by withdrawal of IL-3 from Ba/F3 cells. Withdrawal of growth factors triggers the autophagic pathway in many different cell types. ${ }^{29} \mathrm{Ba} / \mathrm{F} 3$ is a murine hematopoietic cell line that is dependent on interleukin-3 (IL-3) for its growth. ${ }^{30} \mathrm{We}$ monitored autophagy in these cells upon IL-3 deprivation, using processing of cytosolic microtubule-associated protein light chain-3 (LC3)-I into LC3-II as an autophagy-specific marker. $^{31,32}$ Consistent with a recent report, ${ }^{33}$ IL-3 deprivation was associated with increased autophagy during the first $8 \mathrm{~h}$, as evidenced by increased LC3-II levels (Figure 1a). Note that basal levels of LC3-II could be
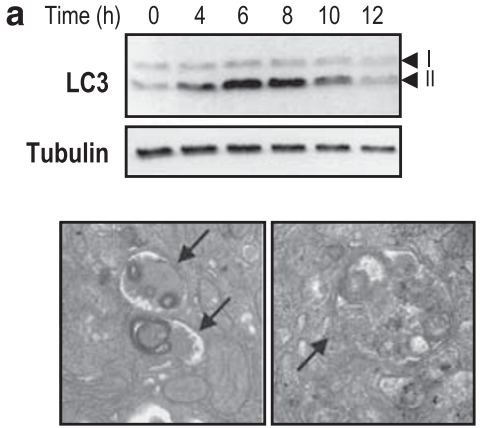

C

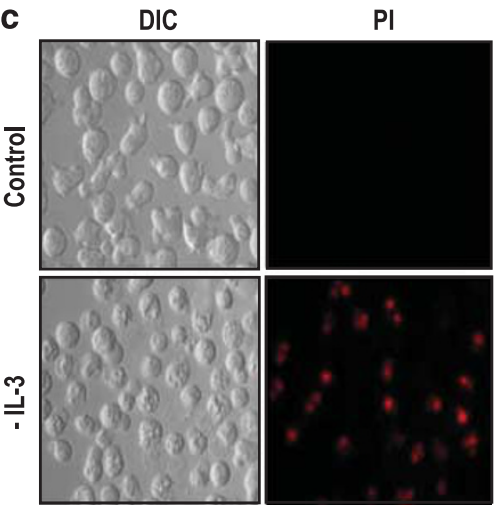

b

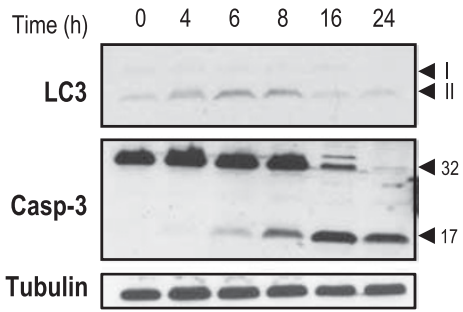

d

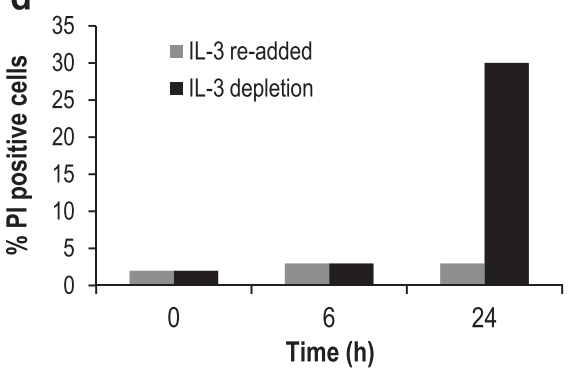

Figure 1 Autophagy precedes apoptosis induced in $\mathrm{Ba} / \mathrm{F} 3$ cells by IL-3 withdrawal. (a) Ba/F3 WT cells were deprived of IL-3 for the indicated durations. Protein samples were prepared and analyzed by western blotting using anti-LC3 and anti-tubulin antibodies. TEM images of autophagic vacuoles in Ba/F3 cells depleted of IL-3 for $6 \mathrm{~h}$. (b) At several time points after IL-3 deprivation of Ba/F3 cells, cellular extracts were prepared and analyzed by immunoblotting with anti-LC3, anti-caspase-3 and anti-tubulin antibodies. (c) Ba/F3 cells were incubated in complete medium (control) or medium lacking IL-3, and examined microscopically after $24 \mathrm{~h}$. Dying cells were visualized by uptake of PI. Note the condensed nuclei. (d) Six hours after IL-3 depletion, the medium was left untouched or was re-supplemented with IL-3. PI-positive cells were measured by flow cytometry at 0,6 and $24 \mathrm{~h}$ 
detected even in the presence of IL-3 (0-h time point in Figure 1a), which reflects regulation of cellular homeostasis by autophagy. Transmission electron microscopy (TEM) analysis of $\mathrm{Ba} / \mathrm{F} 3$ cells deprived of IL-3 for $6 \mathrm{~h}$ confirmed the presence of autophagosomes, recognized as double membrane-bound vacuoles engulfing cytosolic contents or organelles (Figure 1a). Sustained IL-3 deprivation induces the apoptotic mitochondrial pathway ${ }^{30,34}$ followed by activation of executioner casps about 6 to $8 \mathrm{~h}$ posttreatment, as monitored by detecting processed casp-3 on western blot (Figure 1b). The plasma membrane eventually lost its integrity (Figure 1c). Interestingly, restitution of IL-3 after $6 \mathrm{~h}$ of depletion rescued the cells from death, as assessed by propidium iodide (PI) exclusion (Figure 1d). This indicates that activation of autophagy per se does not result in cell death in these cells. Notably, reduced levels of LC3-II were observed $10 \mathrm{~h}$ after growth factor deprivation (Figure 1a), indicating that autophagy levels are diminished once casp-3 is activated. Together, these data demonstrate that growth factor depletion of $\mathrm{Ba} / \mathrm{F} 3$ cells induces autophagy as a pro-survival mechanism, but apoptotic cell death follows if deprivation is sustained.

Beclin-1 and PI3KC3 are cleaved during apoptosis. As autophagy precedes apoptosis induced by IL-3 withdrawal, we used this cellular model system to study the fate of the autophagy proteins Beclin-1 and PI3KC3. We observed that Beclin-1 and PI3KC3 are cleaved in Ba/F3 cells deprived of IL-3 (Figure $2 \mathrm{a}$ ). After 12 to $16 \mathrm{~h}$ of IL-3 deprivation, fulllength Beclin-1 (Beclin-1-FL) was cleaved into three major fragments of 50,37 and $35 \mathrm{kDa}$, which accumulated with time. For PI3KC3 (105 kDa) two cleavage fragments of about $50 \mathrm{kDa}$ were detected (Figure 2a). Proteolysis of Beclin-1 and PI3KC3 coincided with casp-3 maturation and cleavage of poly-ADP (adenosine diphosphate)-ribose polymerase (PARP) (Figure 2a).

Apoptosis-associated cleavage of Beclin-1 and PI3KC3 is not restricted to IL-3 deprivation of $\mathrm{Ba} / \mathrm{F} 3$ cells, since we also observed cleavage using other cell lines and/or proapoptotic triggers. In both murine (Ba/F3, FDCP1) and human (U937) cell lines, Beclin-1 and PI3KC3 are cleaved during apoptosis induced by growth factor or serum deprivation (Figure $2 b$ and c). In addition, doxorubicin, etoposide and anti-Fas treatment of $\mathrm{Ba} / \mathrm{F} 3$ cells elicited a similar Beclin-1 cleavage pattern (Figure $2 \mathrm{~d}$ and $\mathrm{e}$ ), indicating that this event occurs independently of the cell type and the apoptotic trigger.

Beclin-1 and PI3KC3 cleavage during apoptosis is mediated by casps. Casps are the main proteases activated during apoptotic signaling. ${ }^{12}$ As cleavage of Beclin-1 and PI3KC3 occurred simultaneously with casp activation, we investigated whether these proteins are targets of casp-mediated proteolysis. Blocking casp activity with carbobenzoxy-valyl-analyl-aspartyl-[O-methyl]fluoromethylketone (zVAD-fmk) prevented the processing of PI3KC3, which points to the involvement of casps in its cleavage (Figure 3a). Pretreatment of $\mathrm{Ba} / \mathrm{F3}$ cells with zVAD-fmk also prevented the generation of the 37 and 35kDa Beclin-1 fragments (Figure 3b). In contrast, the 50-kDa fragment was still detected by western blotting, indicating a
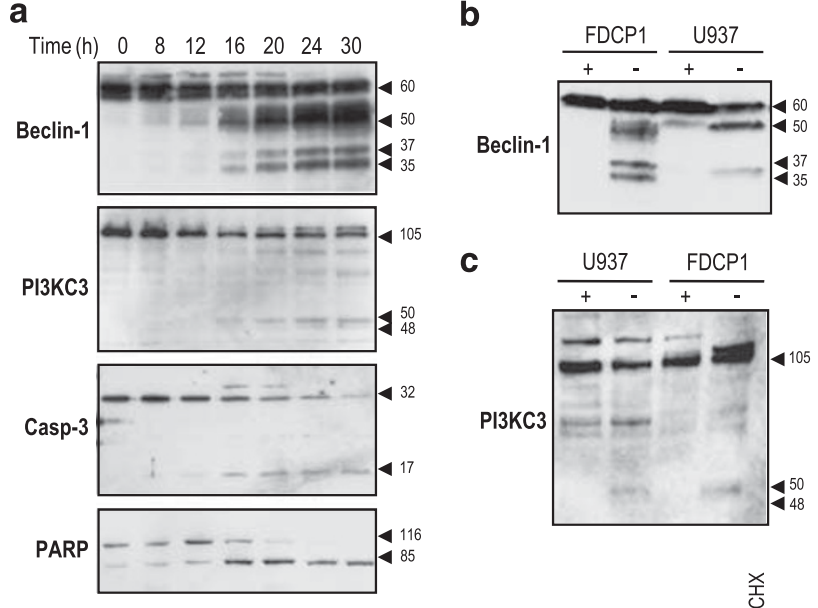

C

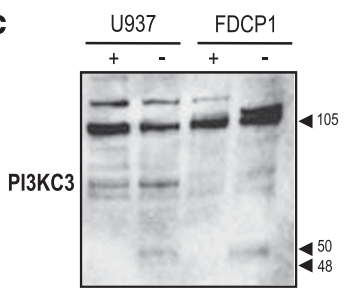

d
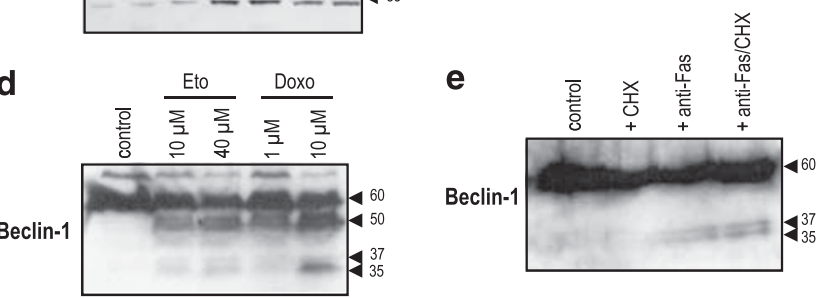

Figure 2 Beclin-1 and PI3KC3 are cleaved during apoptosis. (a) Whole-cell lysates were prepared from Ba/F3 cells deprived of IL-3 for $0,8,12,16,20,24$ or $30 \mathrm{~h}$ and analyzed by western blotting with anti-Beclin-1, anti-PI3KC3, anti-caspase3 and anti-PARP antibodies. (b) Anti-Beclin-1 and (c) anti-PI3KC3 immunoblot analysis of IL-3-deprived FDCP1 cells and serum-starved U937 cells. (d and e) Western blot analysis showing Beclin- 1 cleavage after treatment of $\mathrm{Ba} / \mathrm{F} 3$ cells with etoposide and doxorubicin (d) or anti-Fas $( \pm \mathrm{CHX})(\mathbf{e})$. Eto, etoposide; doxo, doxorubicin; $\mathrm{CHX}$, cycloheximide

that it is generated by another protease. To explore whether these components of the autophagy-inducing complex are direct casp substrates, in vitro-translated Beclin-1 and PI3KC3 were incubated with active recombinant casps. Upon incubation with recombinant casp-3, 7 and 8, PI3KC3 was cleaved into $50-$ and $48-\mathrm{kDa}$ fragments (Figure $3 \mathrm{c}$ ). Casp-3, 7 and 8 also directly cleaved Beclin- 1 into fragments of 37 and/or $35 \mathrm{kDa}$ similar to those detected in apoptotic cells (Figure $3 \mathrm{~d}$ ). In silico analysis of the Beclin-1 protein sequence revealed several classical casp recognition sites: of these, cleavage after TDVD ${ }^{133}$ and DQLD ${ }^{149}$ would generate fragments of 37 and $35 \mathrm{kDa}^{35}$ These potential cleavage sites, which lie immediately downstream from the $\mathrm{BH} 3$ domain, are completely conserved between mouse and human Beclin-1 (Figure 3e). Substitution of $D^{133}$ and $D^{149}$ completely abrogated the cleavage of Beclin-1 by casp-3 and 8 (Figure 3f). Substitution of $D^{149}$ abrogated the generation of the 35-kDa fragment only, indicating that two cleavage sites are involved (Supplementary Figure 1). Therefore, we conclude that the $35-$ and $37-\mathrm{kDa}$ Beclin-1 fragments generated during apoptosis are C-terminal Beclin-1 fragments resulting from casp-mediated cleavage at $D^{149}$ and $D^{133}$, respectively.

Casp-mediated Beclin-1 fragments cannot induce autophagy. Next, we investigated whether casp-mediated cleavage of Beclin-1 affects its autophagy-inducing function. Based on the identification of the casp-cleavage sites, we 

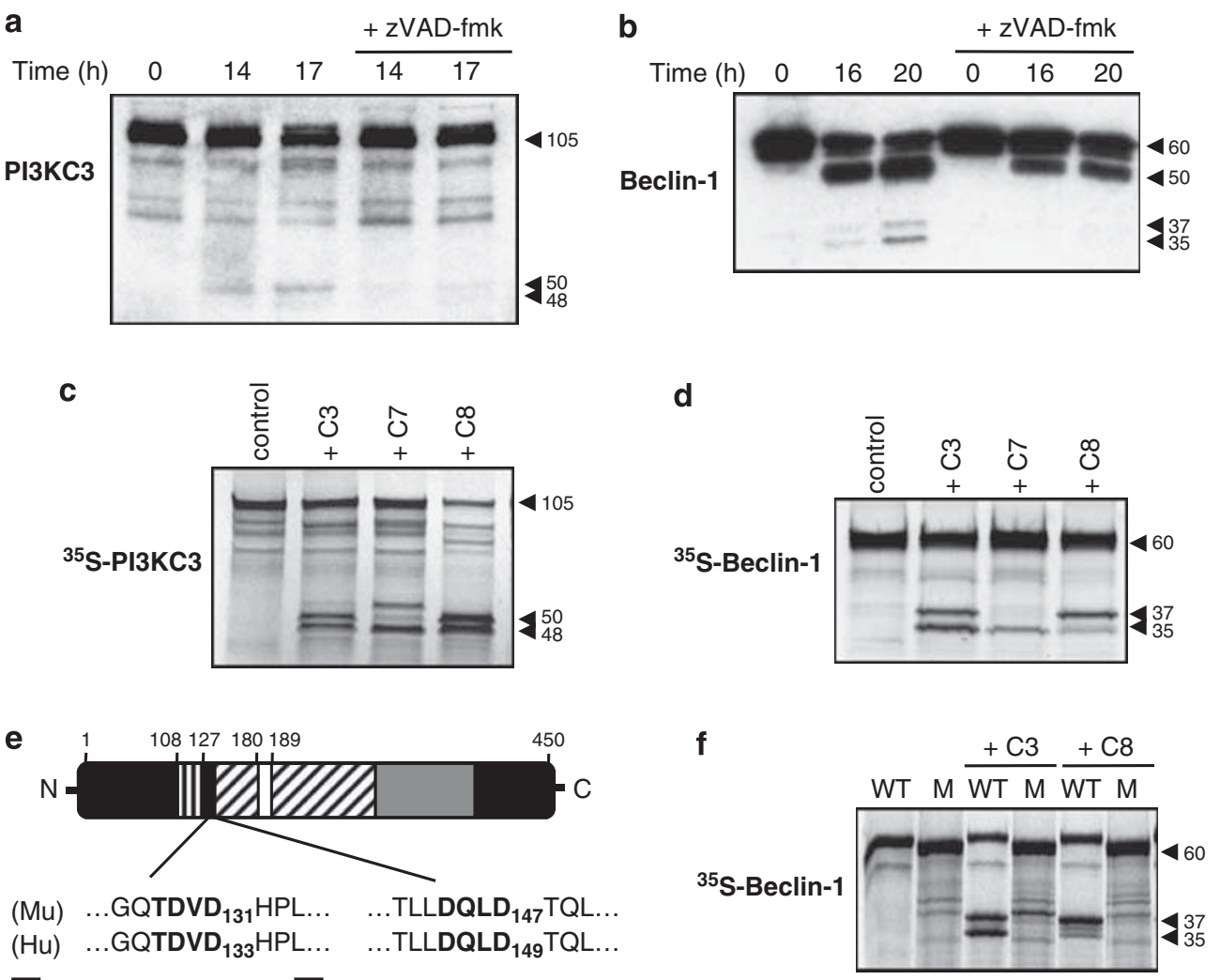

$\begin{array}{ll}\text { MH3 domain } & \square \text { Nuclear export signal } \\ \square \text { Coiled-coil domain } \quad \square \text { Evolutionarily conserved domain }\end{array}$

Figure 3 Cleavage of Beclin-1 and PI3KC3 is mediated by caspases. (a, b) IL-3-deprived Ba/F3 cells were cultured in the absence or presence of $25 \mu \mathrm{M}$ of $\mathrm{ZVAD}$-fmk for 0,16 or $20 \mathrm{~h}$. Cell lysates were prepared and western blotting was performed with anti-PI3KC3 antibody (a) or anti-Beclin-1 antibody (b). (c) PI3KC3 and (d) Beclin-1 were transcribed and translated in vitro in the presence of ${ }^{35} \mathrm{~S}$-methionine and then left untreated or incubated with $300 \mathrm{nM}$ of recombinant casp-3,7 or 8 . The cleavage fragments were analyzed by SDS-PAGE and autoradiography. (e) A scheme representing Beclin-1. Sequence alignment of murine and human Beclin-1 shows conservation of the casp cleavage sites, TDVD and DQLD. The casp-dependent cleavage sites are indicated in bold. The nuclear export signal (NES), BH3, coiled-coil domain (CCD) and evolutionarily conserved domain (ECD) are depicted. (f) Autoradiography of ${ }^{35} S$-labeled Beclin-1 (WT) and Beclin-1-D ${ }^{149} A / D^{133} A$ mutant (M), which were left untreated or were incubated with $300 \mathrm{nM}$ recombinant casp-3 or 8

generated expression vectors to express Beclin-1-FL, Beclin1-N (aa 1-133) and Beclin-1-C (aa 150-450). These vectors were transfected separately into HeLa cells but together with GFP-LC3. Expression of the Beclin-1 constructs was confirmed by western blotting (Figure 4a), and induction of autophagy was measured by microscopic monitoring of GFPLC3 dots (Figure 4b-f). Overexpression of Beclin-1-FL resulted in about threefold increase in GFP-LC3 dots in comparison with the control cells (Figure $4 b, c$ and g). No increase in autophagic activity was observed after transfection of Beclin-1-N and/or Beclin-1-C, indicating that the caspase-mediated cleavage fragments of Beclin-1 cannot activate the autophagic pathway (Figure $4 b, d$, e and g).

Beclin-1-C localizes to the mitochondria. To investigate whether casp-mediated Beclin-1 processing altered its subcellular localization, we performed subcellular fractionation of $\mathrm{Ba} / \mathrm{F} 3$ cells deprived of IL-3. Western blot analysis illustrates that the 37 and $35-\mathrm{kDa}$ fragments accumulated only in the fraction enriched for mitochondria, as determined by detection of Cox-IV (mitochondrial marker) and p44/42 (cytosolic marker) (Figure 5a). Beclin-1-FL was also detected in the mitochondrial fraction, although this fraction contained some cytosolic contamination as shown by detection of $p 44 / 42$. To further characterize the subcellular localization of Beclin-1-C, we performed immunocytochemistry on HeLa cells expressing Beclin-1-FL, Beclin-1-N or Beclin-1-C. While Beclin-1-FL staining was predominantly cytosolic and to a minor extent mitochondrial, all Beclin-1-N accumulated in the nucleus and Beclin-1-C localized at the mitochondria (Figure 5b). These observations were confirmed by line profiles of relative fluorescence intensities showing almost complete overlap between Beclin-1-C (green) and MitoTracker Red, and between Beclin-1-N (green) and the nucleus (blue) (Figure 5c). There was nearly no overlap between Beclin-1FL and MitoTracker Red or the nucleus. Our combined data demonstrate intracellular redistribution of Beclin-1 upon caspase cleavage, resulting in nuclear localization of Beclin-1-N and accumulation of Beclin-1-C at the mitochondria.

Beclin-1-C sensitizes $\mathrm{Ba} / \mathrm{F} 3$ cells to apoptosis induced by IL-3 deprivation. To study the functional consequence of the generation of Beclin-1-C during apoptosis induced by 
IL-3 withdrawal, we generated $\mathrm{Ba} / \mathrm{F} 3$ stable cell lines expressing Beclin-1-FL (FL-1, FL-2, FL-3) or Beclin-1-C (C-1, C-2, C-3). Stable GFP-expressing Ba/F3 cells served as negative control. All cell lines were incubated in IL-3depleted growth medium and cell death was monitored. Upon IL-3 depletion, Ba/F3 clones expressing Beclin-1-FL
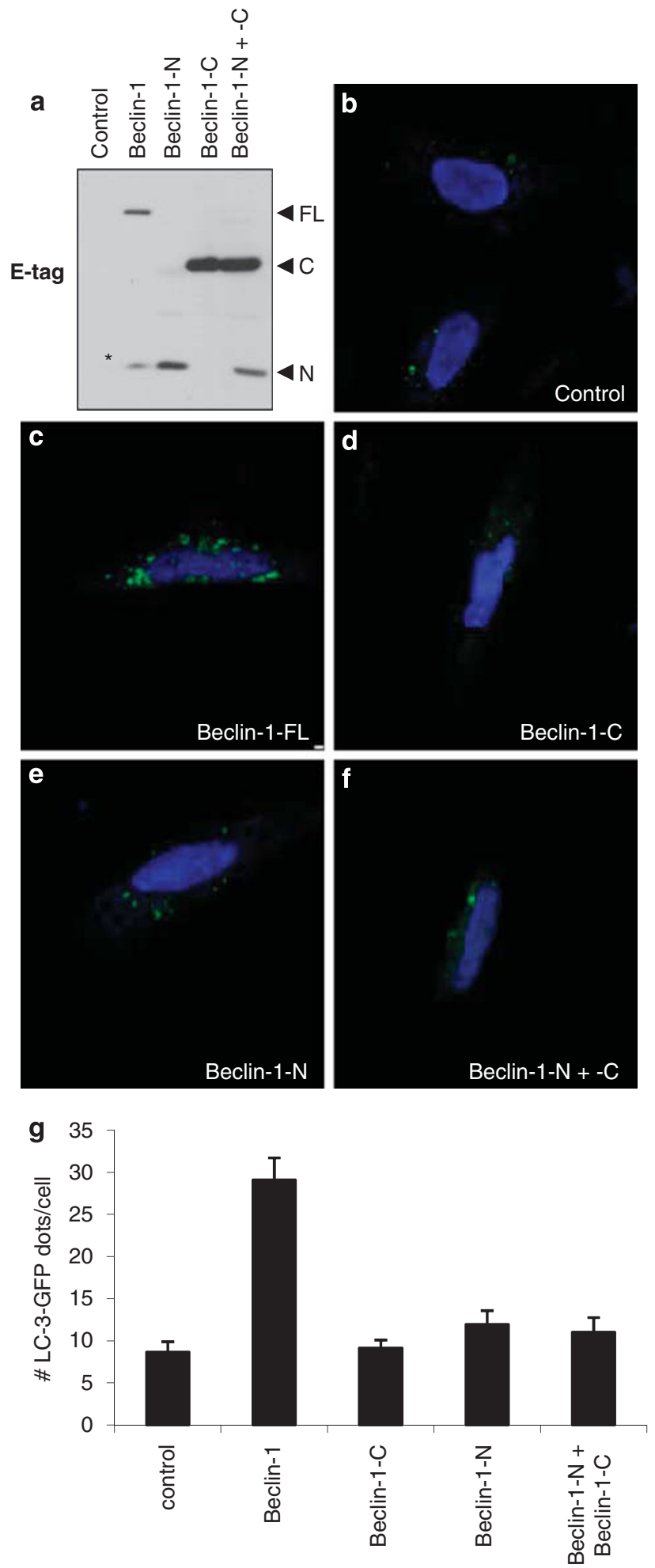

were unaffected (Figure 6a), but clones expressing Beclin-1-C showed up to $45 \%$ enhancement of the apoptotic response (Figure $6 \mathrm{a}$ ). This sensitization was dose-dependent, as enhancement of apoptosis correlated with the levels of Beclin-1-C expression.

Beclin-1-C induces the release of cyt $c$ from isolated mitochondria. The previous observations that Beclin-1-C translocates to the mitochondria upon IL-3 withdrawal and sensitizes to IL-3 deprivation-induced apoptosis, prompted us to investigate whether it can induce the release of proapoptotic factors from mitochondria. We first expressed Beclin-1-FL, Beclin-1-N and Beclin-1-C in Escherichia coli and purified the recombinant proteins as described in the experimental section (Supplementary Figure 2). Next, the recombinant preparations were incubated with isolated mitochondria from liver and the supernatant was analyzed for the presence of cyt $c$ and HtrA2/Omi by immunoblotting. tBid-induced release of cyt $c$ and HtrA2/Omi served as positive control (Figure 6b). ${ }^{36}$ Remarkably, addition of nanomolar amounts of recombinant Beclin-1-C to isolated mitochondria induced the release of cyt $c$ and HtrA2/Omi, (Figure 6c). Small amounts of cyt $c$ and HtrA2/Omi were released from mitochondria upon incubation with recombinant Beclin-1-FL. However, as Beclin-1-FL localizes predominantly in the cytosol (Figure 5) and has no sensitizing effect on apoptosis (Figure 6a), Beclin-1-FL probably does not engage the mitochondrial cell death pathway. To conclude, our data suggest that casp-mediated cleavage of Beclin-1 results in the localization of Beclin-1-C fragments at the mitochondria, sensitizing to apoptosis by enhancing the release of mitochondrial pro-death factors.

\section{Discussion}

Cells of the bone-marrow-derived pro-B-cell line Ba/F3 die apoptotically upon IL-3 withdrawal. ${ }^{30,37}$ In line with a recent report, ${ }^{33}$ we show induction of autophagy soon after IL-3 withdrawal and before the propagation of apoptosis. Stressinduced autophagy is a mechanism that, depending on cell type and stimulus, either promotes or counteracts cell death. $^{22}$ Under conditions of growth factor starvation, when cellular self-maintenance is impeded, autophagy breaks down unnecessary proteins and damaged organelles to recycle metabolites to keep mitochondrial ATP production and maintain viability of the cells; here autophagy plays a prosurvival role. ${ }^{21,38}$ Also in Ba/F3 cells, restoration of IL-3 after

\footnotetext{
Figure 4 Casp-mediated Beclin-1 cleavage inactivates its autophagic function. (a-f) HeLa cells were transfected with GFP-LC3 in combination with Beclin-1-FL, Beclin-1-N, Beclin-1-C or Beclin-1-N and Beclin-1-C. (a) Western blot showing expression of E-tagged Beclin-1-FL, Beclin-1-N and Beclin-1-C. A Beclin-1 fragment corresponding in size to Beclin-1-N could be detected in the Beclin-1-FL setup and is indicated by an asterisk. This fragment is probably due to background levels of cell death caused by the transfection process. (b-f) $24 \mathrm{~h}$ after transfection, cells were fixed and analyzed by confocal microscopy to detect GFP-LC3 dots. (g) The presence of GFP-LC3 dots was scored in 25 to 50 cells. The average number of GFP-LC3 dots per cell is shown, with error bars indicating S.E.M. The number of GFP-LC3 dots in cells expressing Beclin-1-FL was significantly more than that in all other samples $(P$-value $<0.001)$
} 
a
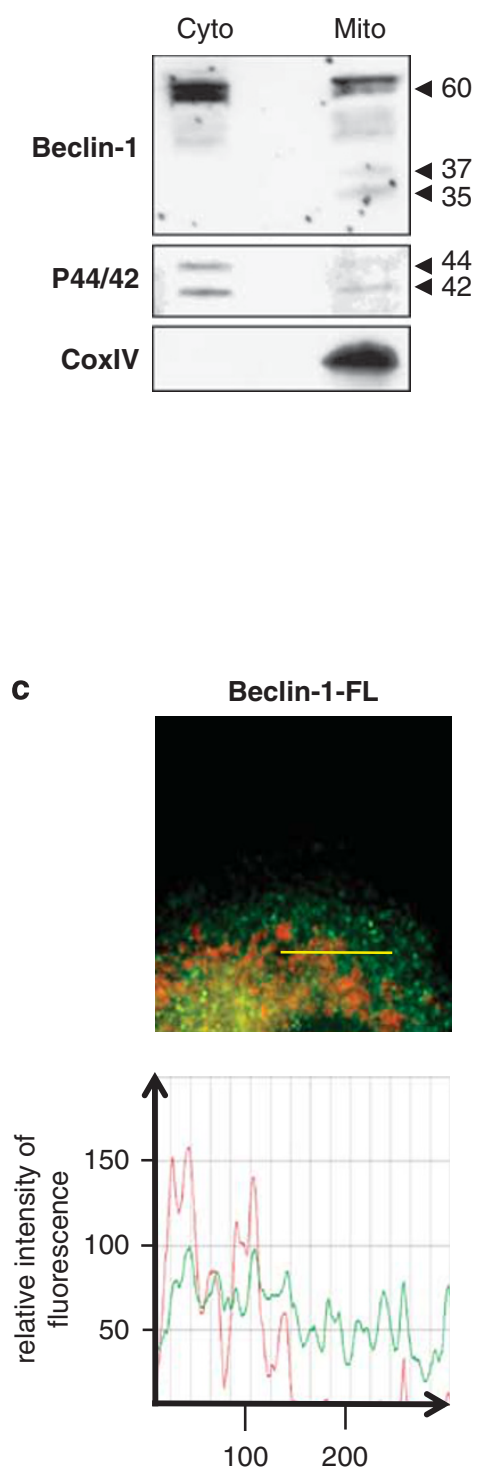

b
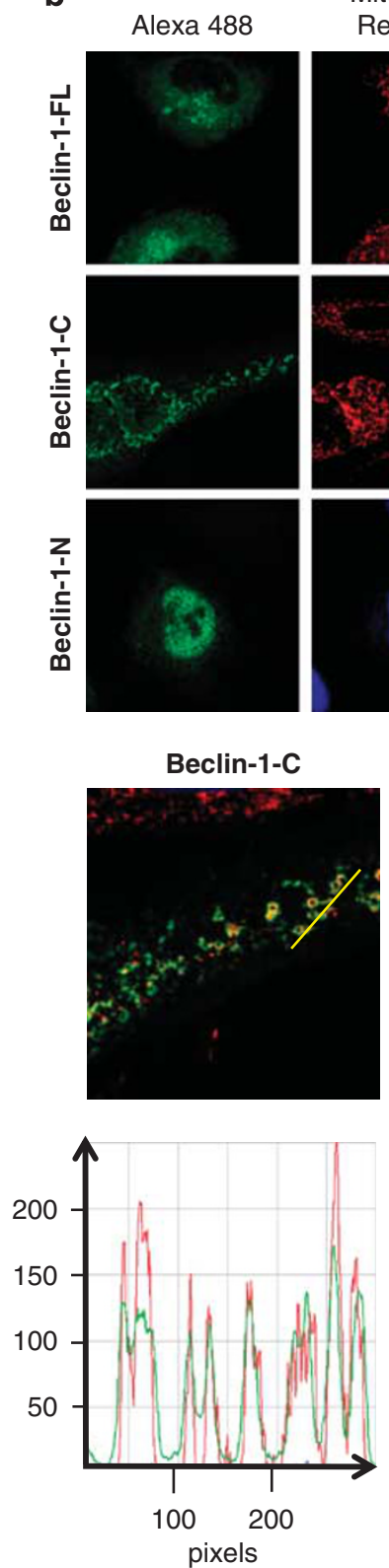

Mitotracker
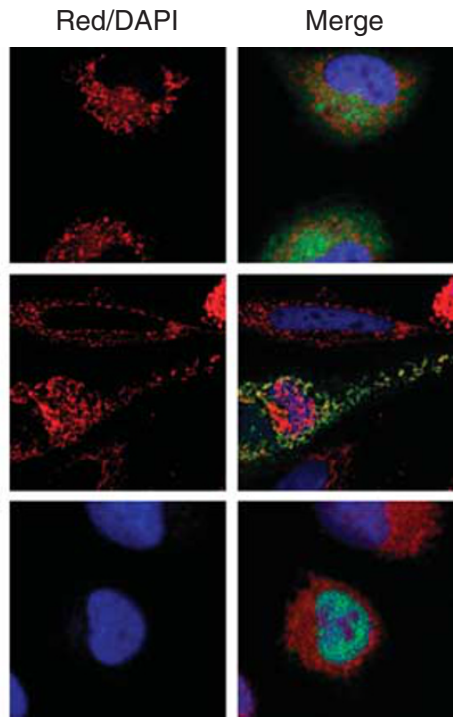

Beclin-1-N
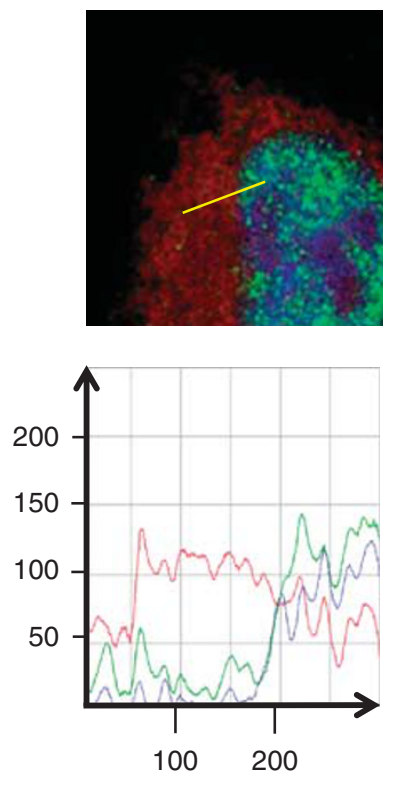

Figure 5 Delocalization of casp-mediated Beclin-1 fragments. (a) Ba/F3 cells were depleted of IL-3 for $16 \mathrm{~h}$ and subjected to subcellular fractionation. The cytosolic and mitochondrial fractions were analyzed by western blotting using anti-Beclin-1, anti-p44/42 and anti-Cox-IV antibodies. (b) Confocal microscopy images of HeLa cells expressing E-tagged Beclin-1-FL, Beclin-1-N or Beclin-1-C. Beclin-1 proteins were labeled with green-fluorescent Alexa Fluor-488, mitochondria were visualized with MitoTracker Red CMXRos and nuclei with DAPI (blue). An overlay is presented in the 'Merge' panel. (c) Detailed colocalization of MitoTracker (red) and DAPI (blue) with Beclin-1-FL, Beclin-1-C and Beclin-1-N (green), shown by a line profile of relative fluorescence intensities

$6 \mathrm{~h}$ of deprivation prevented the cells from dying by apoptosis. At the time of IL-3 re-addition, autophagy was clearly ongoing, which implies that induction of autophagy in these cells does not necessarily lead to cell death but acts as a pro-survival mechanism. We used this cellular model system to further investigate the possible link between autophagy and apoptosis. The apoptotic phase is characterized by the cleavage of two key components of the autophagy-inducing PI3KC3 complex, Beclin-1 and PI3KC3. It was recently suggested that Beclin-1 is cleaved by casps because zVAD-fmk could reverse the decline in Beclin-1 expression levels during tumor necrosis factor-related apoptosis-inducing ligand (TRAIL)induced apoptosis in HeLa cells. ${ }^{39}$ Moreover, $D^{149}$ was reported as a casp cleavage site in Beclin-1. ${ }^{40}$ We report two casp cleavage sites downstream from the $\mathrm{BH} 3$ domain (aa 108-127) at $D^{133}$ and $D^{149}$, which explains the generation of the 37 and $35-\mathrm{kDa}$ C-terminal fragments during apoptosis. Besides these fragments, a Beclin-1 fragment of $50 \mathrm{kDa}$ was detected upon induction of apoptosis in Ba/F3 cells, although this cleavage could not be attributed to casp-mediated 


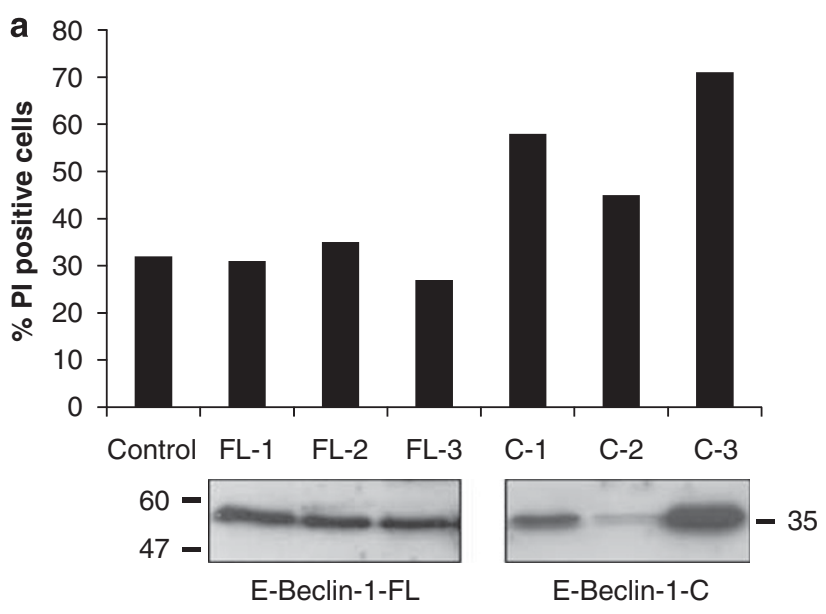

b

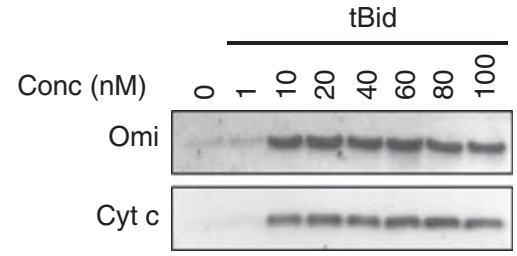

c

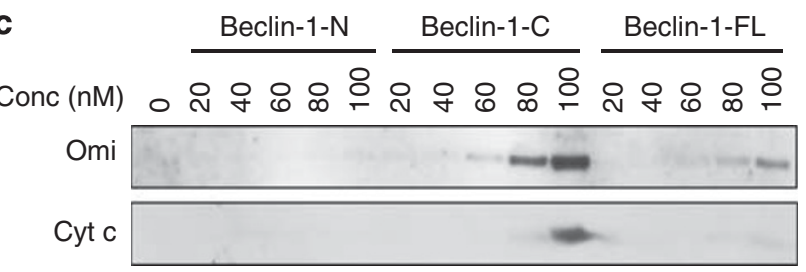

Figure 6 Beclin-1-C enhances apoptosis and induces cyt $c$ release from isolated mitochondria. (a) Ba/F3 cell lines stably expressing GFP (control), E-tagged Beclin-1-FL (FL-1, FL-2, FL-3) or Beclin-1-C (C-1, C-2, C-3) were cultured in the absence of IL-3 for $16 \mathrm{~h}$ and the percentage of PI-positive cells was determined by flow cytometry. Beclin-1-FL and Beclin-1-C expression levels were analyzed by western blotting using anti-E tag antibody. Results are representative of three independent experiments. (b-c) Mitochondria were isolated from murine livers and incubated with the indicated concentrations of recombinant tBid (b), Beclin-1-FL, Beclin-1-N or Beclin-1-C (c). The post-mitochondrial supernatant was analyzed by western blotting using anti-cyt $c$ and anti-HtrA2/Omi

proteolysis. Calpains might be responsible because a similar $50-\mathrm{kDa}$ fragment could be generated by recombinant $\mu$-calpain from in vitro-translated Beclin-1 (Supplementary Figure 3). Interestingly, it is known that during apoptosis calpains are involved in the cleavage of another Atg protein, Atg5, which functions downstream from Beclin-1 during the formation of autophagosomes. ${ }^{38,41-43}$

Once apoptosis is initiated in IL-3-deprived $\mathrm{Ba} / \mathrm{F} 3$ cells and casps are active, LC3-II levels are severely diminished. Here, we demonstrate that Beclin-1 cleavage can contribute to inhibition of autophagy during apoptosis. In contrast to Beclin1-FL, neither Beclin-1-N nor Beclin-1-C could activate autophagy. ${ }^{40}$ In addition, we demonstrate delocalization of both Beclin-1 fragments. Beclin-1-N localized predominantly at the nucleus, which may be explained by the loss of the N-terminal nuclear export signal (aa 180-189) after cleavage. ${ }^{44}$ Beclin-1-C accumulated at the mitochondria. This is rather paradoxical because the $\mathrm{BH}$ domain (aa 107-135) mediating the binding with $\mathrm{Bcl}-2$ and $\mathrm{Bcl}-\mathrm{x}_{\mathrm{L}}$ is removed from the C-terminal part by casp cleavage. ${ }^{26,27}$ Mounting evidence demonstrates cleavage of several crucial autophagy-related proteins during apoptosis, including Atg5, Atg4D, PI3KC3 and Beclin-1. ${ }^{43,45}$ These processing events probably lead to a general demolition of the autophagy machinery. Besides observing inactivation of the autophagic activity of Beclin-1$\mathrm{FL}$, we also observed strong sensitization to apoptosis induced by growth factor deprivation in cells expressing Beclin-1-C. This sensitization was not evident when Beclin-1FL was overexpressed, which is in line with a recent report demonstrating that overexpression of Beclin-1 does not affect apoptosis. ${ }^{46}$ Moreover, it has been reported that Beclin-1 deficiency in ES cells does not result in any change in the apoptotic process induced by UV irradiation. ${ }^{8}$

To shed light on how Beclin-1-C accelerates apoptosis, we studied the effect of recombinant Beclin-1-C on the integrity of mitochondria. We found that Beclin-1-C triggered the mitochondria to release proapoptotic factors such as $\mathrm{HtrA2/Omi}$ and cyt $c$. In view of the BH3-mediated binding of Beclin-1 to $\mathrm{Bcl}-2 / \mathrm{Bcl}-\mathrm{x}_{\mathrm{L}}{ }^{26,27,47,48}$ it is conceivable that this interaction sequesters Beclin-1-FL from a proapoptotic function in cells. Casp-dependent cleavage generates a BH3-free Beclin-1-C fragment that can perform its proapoptotic function by triggering cyt $c$ release. Our combined results demonstrate that caspase-mediated cleavage of Beclin-1 establishes the crosstalk between autophagy and apoptosis. Cleavage of Beclin-1 during apoptosis not only inactivates its autophagic function, but also generates a Beclin-1-derived fragment that translocates to the mitochondria and sensitizes cells to IL-3 deprivation-induced apoptosis, probably by enhancing the release of HtrA2/Omi and cyt $c$ (Figure 7). A similar observation has been reported for Atg5: calpain-mediated cleavage of Atg5 results in a truncated protein that can induce apoptosis by interacting with $\mathrm{Bcl}-\mathrm{x}_{\mathrm{L}}$ at the mitochondria. ${ }^{43}$ Since the $\mathrm{BH} 3$ domain is not present in Beclin-1-C, the mechanism by which Beclin-1-C triggers the release of prodeath factors is still under investigation. In contrast to Atg5, ${ }^{43}$ expression of Beclin-1-C is not sufficient to induce cell death. Only when cells are depleted of IL-3 does the proapoptotic effect of Beclin-1-C become obvious. Therefore, it will also be worthwhile to investigate which proteins are involved in targeting Beclin-1-C to the mitochondria, and to explore the mechanism by which Beclin-1-C triggers the mitochondria to release proapoptotic factors. Most probably, other autophagyrelated proteins are subjected to cleavage after induction of cell death and function synergistically to enhance the apoptotic response. Further investigation of these cleavage events will be important for gaining greater knowledge of the interrelationship between autophagy and apoptosis.

\section{Materials and Methods}

Plasmids. The cDNA encoding human Beclin-1 was amplified by reverse transcription PCR from a HeLa CDNA library using primers $5^{\prime}$-ATA AGAATGCGGCCGCTATGGAAGGGTCTAAGACGTCCAACAAC-3' and $5^{\prime}$-TGC GGTCGACTCATTTGTTATAAAATTGTGAGGACACC- ${ }^{\prime}$. The amplified product was cloned in the pCAGGS-E vector in frame with the N-terminal E-tag. CDNA encoding Beclin-1-N (aa 1-133) and Beclin-1-C (aa 150-450) were cloned similarly using the following primers: Beclin-1-N forward: 5'-ATAAGAATGCGGCCG CTATGGAAGGGTCTAAGACGTCCAACAAC- $3^{\prime}$ and Beclin-1-N reverse: $5^{\prime}$-TA CGCGTCGACTCAATCCACATCTGTCTGGCCCGACAT-3'; Beclin-1-C forward: 


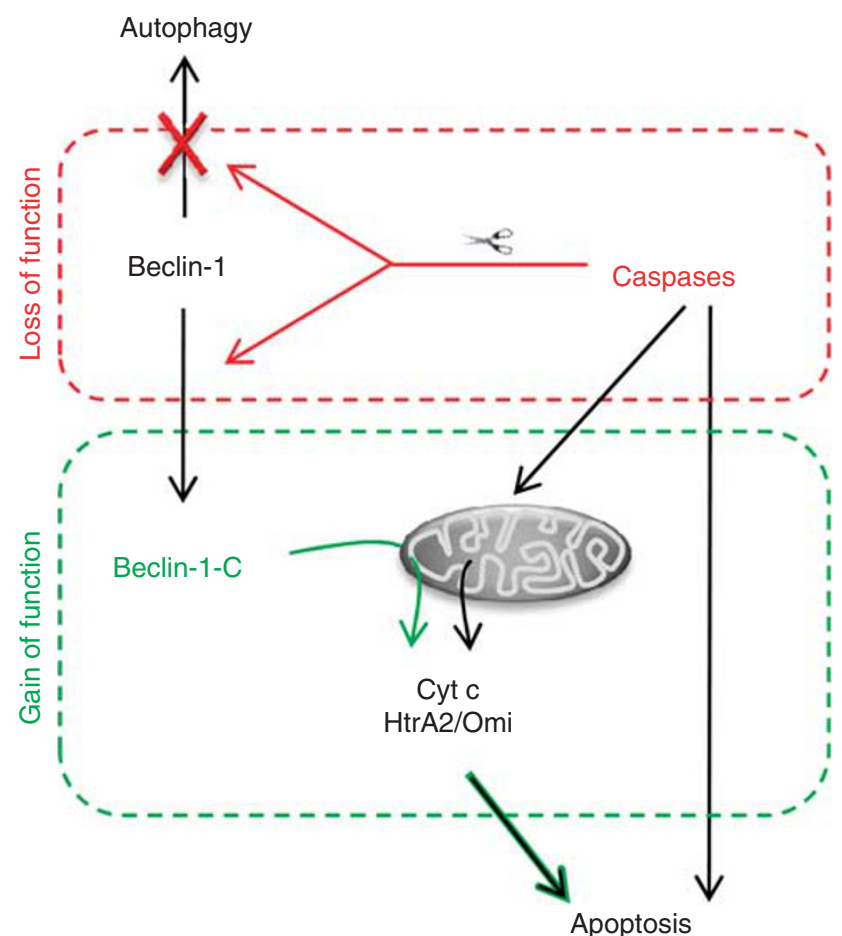

Figure 7 Proposed model of Beclin-1 cleavage in IL-3-deprived Ba/F3 cells. Induction of apoptosis results in casp-mediated cleavage of Beclin-1. Beclin-1 cleavage inactivates its autophagic function and induces delocalization of Beclin-1-C to the mitochondria. At the mitochondria, Beclin-1-C accelerates apoptosis, probably by enhancing the release of cyt $c$ and $\mathrm{HtrA2/Omi}$

5'-ATAAGAATGCGGCCGCAATGACTCAAGCTCA-3' and Beclin-1-C reverse: 5'- TGCGGTCGACTCATTTGTTATAAAATTGTGAGGACACC-3'. pEF6-Beclin-1myc-His, used for TNT, was constructed by inserting a Kpnl-Notl fragment containing human Beclin-1 without a termination codon between the Kpnl and Notl sites of pEF6-myc-His. The cDNA encoding the Beclin-1-D ${ }^{133} A-D^{149} A$ mutant was constructed by site-directed PCR mutagenesis using the following primers: $D^{133} A$ forward: $5^{\prime}$-ATGTCGGGCCAGACAGATGTGGCTCACCCACT- $3^{\prime}$ and $\mathrm{D}^{133} \mathrm{~A}$ reverse: $5^{\prime}$-AGTGGGTGAGCCACATCTGTCTGGCCCGACAT- $3^{\prime}$; $\mathrm{D}^{149} \mathrm{~A}$-forward: $5^{\prime}$-ACTCTTTTAGACCAGCTGGCCACTCAGCTC- $3^{\prime}$ and $\mathrm{D}^{149}$ A-reverse: $5^{\prime}$ GAGCTGAGTGGCCAGCTGGTCTAAAAGAGT-3'. The products were cloned in the $p E F 6-m y c-H i s$ vector. Proper construction of all the plasmids was confirmed by DNA sequencing.

Cell culture. The IL-3-dependent mouse pro-B-cell line $\mathrm{Ba} / \mathrm{F} 3$ was maintained in RPMI 1640 medium (Invitrogen, Carlsbad, CA, USA) supplemented with 10\% $(\mathrm{v} / \mathrm{v})$ heat-inactivated fetal calf serum, penicillin $(100 \mathrm{U} / \mathrm{ml})$, streptomycin $(100 \mu \mathrm{g} /$ $\mathrm{ml}$ ) and $10 \%(\mathrm{~V} / \mathrm{v})$ conditioned medium from WEHI-3B cells as a source of mouse IL3. Cells were incubated at $37^{\circ} \mathrm{C}$ in a humidified atmosphere containing $5 \% \mathrm{CO}_{2}$. Similar growth conditions were used for culturing the IL-3-dependent FDCP1 cells. $\mathrm{Ba} / \mathrm{F} 3$ cells were stably transfected by electroporation as described. ${ }^{49}$ Human U937 cells were maintained in RPMI 1640 medium (Invitrogen) supplemented with 10\% $(\mathrm{v} / \mathrm{v})$ heat-inactivated fetal calf serum, penicillin $(100 \mathrm{U} / \mathrm{ml})$ and streptomycin $(100 \mu \mathrm{g} / \mathrm{ml})$. HeLa cells were grown in DMEM medium supplemented with $10 \%(\mathrm{v} / \mathrm{v})$ heat-inactivated fetal calf serum, L-glutamine $(2 \mathrm{mM})$, penicillin $(100 \mathrm{U} / \mathrm{ml})$, streptomycin $(100 \mu \mathrm{g} / \mathrm{ml})$ and sodium pyruvate $(400 \mu \mathrm{M})$.

Etoposide (Alexis Biochemicals, San Diego, CA, USA) and doxorubicin (Sigma, St. Louis, MO, USA) were administered to $\mathrm{Ba} / \mathrm{F} 3$ cells at concentrations of 10 or $40 \mu \mathrm{M}$, and 1 or $10 \mu \mathrm{M}$, respectively, for $16 \mathrm{~h}$. Anti-Fas (anti-mouse Fas, CD95, clone Jo2; Pharmingen, San Diego, CA, USA) was coated on six-well plates at $10 \mu \mathrm{g} / \mathrm{ml}$ in PBS for $24 \mathrm{~h}$ at $4^{\circ} \mathrm{C}$. The wells were washed with RPMl before adding cells. The $\mathrm{Ba} / \mathrm{F} 3$ cells were seeded at 300000 cells per well in uncoated and antiFas coated wells. Untreated cells, cells treated with cycloheximide (CHX) $(0.2 \mu \mathrm{g} /$ $\mathrm{ml}$ ) or $\mathrm{CHX}+$ anti-Fas were lysed after $24 \mathrm{~h}$.
Immunoblot analysis. Cells were washed twice in ice-cold PBS and lysed in ice-cold caspase lysis buffer $(0.05 \%$ Nonidet-P $40,220 \mathrm{mM}$ mannitol, $68 \mathrm{mM}$ sucrose, $2 \mathrm{mM} \mathrm{NaCl}, 2.5 \mathrm{mM} \mathrm{KH}_{2} \mathrm{PO}_{4}, 10 \mathrm{mM}$ HEPES (pH 7.4), supplemented with $0.1 \mathrm{mM}$ PMSF, $200 \mathrm{U} / \mathrm{ml}$ aprotinin, $10 \mathrm{mg} / \mathrm{ml}$ leupeptin and $1 \mathrm{mM}$ oxidized glutathione) or directly in protein loading buffer (125 mM Tris- $\mathrm{HCl}(\mathrm{pH} 6.8), 6 \%$ SDS, $1.4 \mathrm{M} \beta$-mercaptoethanol, $20 \%$ glycerol, $0.01 \%$ bromophenol blue). Samples were boiled for $10 \mathrm{~min}$ before loading. Lysates were separated in SDS-PAGE gels of different percentages and transferred to nitrocellulose membranes by semi-dry blotting in a buffer containing $25 \mathrm{mM}$ Tris- $\mathrm{HCl}(\mathrm{pH} 8.0), 190 \mathrm{mM}$ glycine and $20 \%$ methanol. All further incubations were performed at room temperature on a platform shaker. Blocking, incubation with antibody and washing of the membrane were all performed in PBS supplemented with $0.02 \%$ Tween-20 (v/v) and 3\% (w/v) non-fat dry milk. The primary antibodies used were anti-LC3 (mAb LC3-5F10; Nanotools, Teningen, Germany), anti-Beclin-1 (BD Biosciences, San Diego, CA, USA), antiPI3KC3 (Zymed laboratories, South San Fransisco, CA, USA), anti- $\beta$-tubulin-HRP (Abcam, Cambridge, UK), anti-E-HRP (Amersham Biosciences, Buckinghamshire, UK), anti-caspase-3 (Labaratoire d'Hormonologie Animale, Marloie, Belgium), antiPARP (Biomol, Plymouth Meeting, PA, USA), anti-Flag-horseradish peroxidase (HRP) (Sigma) and anti-cyt $c$ (BD Biosciences). The anti-HtrA2/Omi antibody was prepared as described previously. ${ }^{50}$ Membranes were incubated with HRPconjugated secondary antibodies against mouse and rabbit immunoglobulin (Amersham Biosciences). Immunoreactive proteins were visualized by enhanced chemiluminescence (PerkinEImer, Boston, MA, USA).

Apoptosis assays. Before induction of apoptosis, $\mathrm{Ba} / \mathrm{F} 3$ cells were resuspended in fresh medium at $3 \times 10^{5} \mathrm{cells} / \mathrm{ml}$. The next day, apoptosis was induced by IL-3 depletion for different periods of time. Loss of cell membrane integrity as a measure for cell death was determined by monitoring PI $(30 \mu \mathrm{M})$ uptake at $610 \mathrm{~nm}$ by FACS analysis using a FACScalibur flow cytometer (Becton Dickinson, Sunnyvale, CA, USA) equipped with a 488-nm Argon laser.

In vitro transcription/translation. Recombinant casp-3, 7 and 8 were generated as described. ${ }^{51}$ The plasmids pEF6-Beclin-1-myc-His and pEF6-Beclin1-D133A/D149A-myc-His were used as a template for in vitro coupled transcription/ translation in a rabbit reticulocyte lysate system according to the manufacturer's instructions (Promega, Madison, WI, USA). For detection of the translation products, ${ }^{35} \mathrm{~S}$-methionine was added to the translation reactions. Translation reactions $(2 \mu \mathrm{l}$ each) were incubated with $300 \mathrm{nM}$ recombinant casp- 3,7 or 8 in $24 \mu \mathrm{l}$ of cell-free system buffer (10 mM HEPES- $\mathrm{NaOH}(\mathrm{pH} 7.4), 220 \mathrm{mM}$ mannitol, $68 \mathrm{mM}$ sucrose, $2 \mathrm{mM} \mathrm{NaCl}, 2.5 \mathrm{mM} \mathrm{KH}_{2} \mathrm{PO}_{4}, 0.5 \mathrm{mM}$ EGTA, $2 \mathrm{mM}$ $\mathrm{MgCl}_{2}, 5 \mathrm{mM}$ pyruvate, $0.1 \mathrm{mM}$ PMSF, $200 \mathrm{U} / \mathrm{ml}$ aprotinin, $10 \mathrm{mg} / \mathrm{ml}$ leupeptin) for $1 \mathrm{~h}$ at $37^{\circ} \mathrm{C}$. The cleavage products were analyzed by SDS-PAGE and autoradiography.

Subcellular fractionation. Ba/F3 cells were harvested and washed three times with buffer-A (20 mM MOPS, $1 \mathrm{mg} / \mathrm{ml}$ bovine serum albumin, $1 \mathrm{mM}$ EGTA, $100 \mathrm{mM}$ sucrose) and resuspended in buffer-B (buffer-A plus $100 \mu \mathrm{g} / \mathrm{ml}$ digitonin, $0.1 \mathrm{mM}$ PMSF, $200 \mathrm{U} / \mathrm{ml}$ aprotinin, $10 \mu \mathrm{g} / \mathrm{ml}$ leupeptin, $1 \mathrm{mM}$ sodium orthovanadate, $1 \mathrm{mM}$ sodium fluoride). After homogenization with a dounce homogenizer $B$ pestle, samples were centrifuged twice $\left(2500 \mathrm{~g}, 5 \mathrm{~min}, 4^{\circ} \mathrm{C}\right)$ to remove nuclei and centrifuged again $\left(10000 \times \mathrm{g}, 10 \mathrm{~min}, 4^{\circ} \mathrm{C}\right)$ to obtain the heavy membrane pellet. The supernatant was centrifuged once more $(20000 \times g, 10 \mathrm{~min}$, $4^{\circ} \mathrm{C}$ ) and the soluble part was kept as the cytosol fraction. The heavy membrane pellet was resuspended in $2 \mathrm{ml}$ of $15 \%$ Percoll ( $\mathrm{V} / \mathrm{v}$ ) and loaded on a Percoll gradient $(60-40-23 \%)$. After centrifugation $\left(32000 \times \mathrm{g}, 5 \mathrm{~min}, 4^{\circ} \mathrm{C}\right)$, the mitochondrial fraction was isolated. Protein samples of the different subcellular fractions were analyzed by western blotting.

Immunocytochemistry. A total of $2 \times 10^{5} \mathrm{HeLa}$ cells were grown on glass coverslips in six-well plates (Becton Dickinson, Franklin Lakes, NJ, USA) and transfected with $300 \mathrm{ng}$ E-tagged Beclin-1-FL, Beclin-1-C or Beclin-1-N using Fugene 6 Transfection Reagent (Roche Diagnostics, Vilvoorde, Belgium). After $24 \mathrm{~h}$, cells were incubated for $15 \mathrm{~min}$ at $37^{\circ} \mathrm{C}$ with MitoTracker Red CMXRos (Molecular Probes, Eugene, OR, USA), rinsed briefly with ice-cold PBS and fixed for $15 \mathrm{~min}$ with $3 \%$ paraformaldehyde in PBS at $4^{\circ} \mathrm{C}$. The cells were rinsed and permeabilized using $0.3 \%$ saponin. Subsequently, cells were kept for $30 \mathrm{~min}$ in PBS with $0.1 \%$ saponin and $0.5 \%$ BSA. Anti-E-tag antibody dissolved in PBS with $0.1 \%$ saponin, $0.1 \% \mathrm{BSA}$ and $2 \%$ gelatin was incubated for $1 \mathrm{~h}$ at room temperature. The secondary antibody used was Alexa-488-coupled anti-mouse immunoglobulin 
antibody (Molecular Probes). Finally, cells were treated with Vectashield mounting medium containing 4',6-diamidino-2-phenylindole (DAPI) (Vectorlabs, Burlingame CA, USA). For fluorescence imaging, a Leica SP5 AOBS confocal microscope (DMI 6000 ) with an HCX PL APO $63.0 \times 1.40$ OIL UV objective was used.

Three sequential scans were performed. First, the $405-n m$ UV diode laser was used for the DAPI signal, with an emission band $410-485 \mathrm{~nm}$. Next, Alexa-488 was excited by the $488-\mathrm{nm}$ argon laser and detected at $555 \mathrm{~nm}$ to $625 \mathrm{~nm}$. Finally, the $543 \mathrm{~nm} \mathrm{HeNe}$-laser was used for excitation of Alexa-594 with emission bandwidths set to $570-693 \mathrm{~nm}$. Images were acquired at a resolution of $512 \times 512$ pixels and a pixel size of $142 \mathrm{~nm}$, with six-line-averaging and a pinhole set on 1 Airy Unit. A line profile was generated by measuring fluorescence intensities using AxioVision.

Counting GFP-LC3 dots. A total of $2 \times 10^{5} \mathrm{HeLa}$ cells were grown on glass coverslips in six-well plates (Becton Dickinson) and transfected with $250 \mathrm{ng}$ GFPLC3 and $300 \mathrm{ng}$ E-tagged Beclin-1-FL, Beclin-1-C or Beclin-1-N using Lipofectamine 2000 (Invitrogen, Carlsbad, CA, USA). The medium was refreshed $6 \mathrm{~h}$ after transfection. After $24 \mathrm{~h}$, the cells were incubated for $30 \mathrm{~min}$ at $37^{\circ} \mathrm{C}$ with $100 \mathrm{nM}$ bafilomycin (Sigma Aldrich). The cells were rinsed with PBS, fixed with $1 \%$ paraformaldehyde at $4^{\circ} \mathrm{C}$ for $15 \mathrm{~min}$, incubated with Draq5 (Alexis Biochemicals, San Diego, CA, USA) diluted 1:1000 in PBS for 15 min and treated with FluorSave (Calbiochem, San Diego, CA, USA). For each transfection we analyzed 25-50 cells. $P$-value was determined by ANOVA and post hoc statistical analysis.

Transmission electron microscopy. Cells were fixed in $4 \%$ paraformaldehyde and $2.5 \%$ glutaraldehyde in $0.1 \mathrm{M}$ sodium cacodylate buffer $(\mathrm{pH} 7.2)$ for $4 \mathrm{~h}$ at room temperature and then fixed overnight at $4{ }^{\circ} \mathrm{C}$. After washing in buffer, the cells were post-fixed in $1 \% \mathrm{OsO}_{4}$ with $1.5 \% \mathrm{~K}_{3} \mathrm{Fe}(\mathrm{CN})_{6}$ in $0.1 \mathrm{M}$ sodium cacodylate buffer. After washing, the cells were dehydrated through a graded ethanol series, including bulk staining with 1\% uranyl acetate at the $50 \%$ ethanol step, and then embedded in Spurr's resin. Ultrathin sections of a gold interference color were cut using an ultra microtome (Ultracut E/Reichert-Jung), post-stained with uranyl acetate and lead citrate in a Leica ultrastainer, and collected on formvarcoated copper slot grids. They were viewed with a transmission electron microscope 1010 (JEOL, Tokyo, Japan).

Expression and purification of recombinant Beclin-1-FL, Beclin1-N and Beclin-1-C. cDNA encoding Beclin-1-FL, Beclin-1-N and Beclin-1-C was amplified by using the following primers: Beclin-1-FL forward: $5^{\prime}$-CGGGG TACCCATGGAAGGGTCTAAGACGTCC-3' and Beclin-1-FL reverse: $5^{\prime}$-CGGGAT CCTCATTTGTTATAAAATTGTGAGG-3'; Beclin-1-N forward: 5'-CGGGGTACCC ATGGAAGGGTCTAAGACGTCC-3' and Beclin-1-N reverse: $5^{\prime}$-CGGGATCCTC AATCCACATCTGTCTGGC-3'; Beclin-1-C forward: 5'-CGGGGTACCCATGACTC AGCTCAACGTCACTGAAAATGAG-3' and Beclin-1-C reverse: $5^{\prime}$-CGGGATCC TCATTTGTTATAAAATTGTGAGG-3'. After digestion with Kpnl-BamH, the amplified products were cloned between the $K p n l$ and BamHI sites of the pLHX32 vector in frame with the $\mathrm{N}$-terminal $\mathrm{His}_{6}$-tag and thioredoxine sequence. All plasmids were transformed in E. coli strain MC1061 containing the transcription regulatory plasmid pICA2 (N. Mertens, unpublished data). Cultures growing exponentially at $28^{\circ} \mathrm{C}$ were induced with $1.0 \mathrm{mM}$ isopropyl- $\beta$-Dthiogalactopyranoside and incubated overnight at $20^{\circ} \mathrm{C}$. Cell pellets were resuspended in resuspension buffer $\left(20 \mathrm{mM} \mathrm{Na}_{2} \mathrm{HPO}_{4} \cdot 2 \mathrm{H}_{2} \mathrm{O}(\mathrm{pH} 7.5), 300 \mathrm{mM}\right.$ $\mathrm{NaCl}, 0.5 \%$ (w/v) CHAPS, supplemented with $1 \mathrm{mg} / 100 \mathrm{ml}$ DNase-I (Roche Diagnostics, Mannheim, Germany) and complete, EDTA-free Protease Inhibitor Cocktail Tablets (Roche Diagnostics)) and were lysed by sonication. Insoluble proteins were removed by centrifugation. The supernatant was loaded on a $\mathrm{Ni}^{2+}$ Sepharose 6FF column (GE Healthcare, Piscataway, NJ, USA) pre-equilibrated with buffer-A (20 mM Na $2 \mathrm{HPO}_{4} .2 \mathrm{H}_{2} \mathrm{O}(\mathrm{pH} 7.5), 300 \mathrm{mM} \mathrm{NaCl}, 0.5 \%$ (w/v) CHAPS) containing $20 \mathrm{mM}$ imidazole. Low-strength, metal-binding proteins were removed by washing with buffer-A containing $50 \mathrm{mM}$ imidazole. His-tagged Beclin-1 was eluted from the column with a three-step gradient in buffer- $\mathrm{B}\left(20 \mathrm{mM} \mathrm{Na}_{2} \mathrm{HPO}_{4} \cdot 2 \mathrm{H}_{2} \mathrm{O}(\mathrm{pH}\right.$ 7.5), $20 \mathrm{mM} \mathrm{NaCl}, 0.5 \%$ (w/v) CHAPS) containing 100,200 or $400 \mathrm{mM}$ imidazole. Fractions containing Beclin-1-FL or Beclin-1-C were pooled and purified further on a Superdex 200 column (GE Healthcare, running buffer, buffer-C: $20 \mathrm{mM}$ Tris- $\mathrm{HCl}$ (pH 7.5), $0.5 \%$ (w/v) CHAPS, $150 \mathrm{mM} \mathrm{NaCl}$ ). Fractions containing Beclin-1-N were pooled and loaded on a Source $30 \mathrm{Q}$ column (GE Healthcare) pre-equilibrated with buffer-D (20 mM Tris- $\mathrm{HCl}(\mathrm{pH} 7.5), 0.1 \%(\mathrm{w} / \mathrm{v})$ CHAPS). Bound proteins were eluted with a linear gradient from 0 to $0.5 \mathrm{M} \mathrm{NaCl}$ in buffer-D. Finally, Beclin-1-N was run on a Superdex 200 column in buffer-C. The purity of the fractions was checked by SDS-PAGE followed by Coomassie blue staining and western blot analysis using Penta-His antibody (Qiagen, Hilden, Germany). The fractions containing Beclin-1-FL/-N/-C were pooled and stored at $-70^{\circ} \mathrm{C}$.

Isolation of murine liver mitochondria. C57BL/6 wild-type mice (7 to 12 weeks of age) were used. Livers were homogenized using a Wheaton type- $\mathrm{B}$ douncer in homogenization buffer $\left(5 \mathrm{mM} \mathrm{KH}_{2} \mathrm{PO}_{4}(\mathrm{pH} 7.4), 0.3 \mathrm{M}\right.$ sucrose, $1 \mathrm{mM}$ EGTA, $5 \mathrm{mM}$ 3-[N-morpholino]propanesulfonic acid). Intact cells and nuclei were removed from the homogenates by centrifugation, twice at $1800 \times g$ and once at $3000 \times \mathrm{g}$, each time for $5 \mathrm{~min}$ at $4^{\circ} \mathrm{C}$. The supernatant was spun down at $10000 \times g$ for $10 \mathrm{~min}$ at $4^{\circ} \mathrm{C}$ to precipitate the heavy membrane fraction containing the mitochondria and further purified on a Percoll gradient as described earlier. ${ }^{52}$ The mitochondrial pellet was resuspended in cell-free system buffer $(10 \mathrm{mM}$ HEPES- $\mathrm{NaOH}$ (pH 7.4), $220 \mathrm{mM}$ mannitol, $68 \mathrm{mM}$ sucrose, $2 \mathrm{mM} \mathrm{NaCl}, 2.5 \mathrm{mM}$ $\mathrm{KH}_{2} \mathrm{PO}_{4}, 0.5 \mathrm{mM}$ EGTA, $2 \mathrm{mM} \mathrm{MgCl} 2,5 \mathrm{mM}$ pyruvate, $0.1 \mathrm{mM}$ PMSF, $1 \mathrm{mM}$ dithiothreitol) and kept on ice until used within $1 \mathrm{~h}$ of preparation.

Cyt $c$ release assay. Mitochondria equivalent to $40 \mu \mathrm{g}$ of liver protein were incubated at $37^{\circ} \mathrm{C}$ in $100 \mu \mathrm{l}$ cell-free system buffer for $20 \mathrm{~min}$ with recombinant tBid, Beclin-1-FL, Beclin-1-N or Beclin-1-C. Supernatants were separated from mitochondria by centrifugation at $20000 \times g$ for $10 \mathrm{~min}$ at $4^{\circ} \mathrm{C}$. One-fifth of the supernatant was analyzed by immunoblotting with anti-cyt $c$.

\section{Conflict of interest}

The authors declare no conflict of interest.

Acknowledgements. We thank A Bredan for editing the paper, W Deckers and $E$ Parthoens for help with confocal microscopy and Conor Mc Guire for statistical analysis. This research has been supported by Flanders Institute for Biotechnology (VIB) and several grants. European grants: FP6 ApopTrain, MRTNCT-035624; EC RTD Integrated Project, FP6 Epistem, LSHB-CT-2005-019067; EC RTD Integrated Project, Apo-Sys, FP7-200767; Belgian grants: Interuniversity Attraction Poles, IAP 6/18; Flemish grants: Fonds Wetenschappelijke Onderzoek Vlaanderen, 3G.0218.06 and G.0133.05; Ghent University grants: BOF-GOA12.0505.02 and 01GC0205. TVB and SL currently hold a grant from the 'Fonds voor Wetenschappelijk Onderzoek'.

1. Wang CW, Klionsky DJ. The molecular mechanism of autophagy. Mol Med 2003; 9 : 65-76.

2. Liang $\mathrm{XH}$, Jackson S, Seaman $\mathrm{M}$, Brown $\mathrm{K}$, Kempkes $\mathrm{B}$, Hibshoosh $\mathrm{H}$ et al. Induction of autophagy and inhibition of tumorigenesis by beclin 1. Nature 1999; 402: 672-676

3. Fimia GM, Stoykova A, Romagnoli A, Giunta L, Di Bartolomeo S, Nardacci R et al. Ambra1 regulates autophagy and development of the nervous system. Nature 2007; 447: $1121-1125$

4. Liang C, Feng $\mathrm{P}, \mathrm{Ku}$ B, Dotan I, Canaani D, Oh BH et al. Autophagic and tumour suppressor activity of a novel Beclin1-binding protein UVRAG. Nat Cell Biol 2006; 8: 688-699.

5. Kihara A, Kabeya Y, Ohsumi Y, Yoshimori T. Beclin-phosphatidylinositol 3-kinase complex functions at the trans-Golgi network. EMBO Rep 2001; 2: 330-335.

6. Furuya N, Yu J, Byfield M, Pattingre S, Levine B. The evolutionarily conserved domain of Beclin 1 is required for Vps34 binding, autophagy and tumor suppressor function. Autophagy 2005; 1: 46-52.

7. Sun $Q$, Fan W, Chen K, Ding X, Chen S, Zhong Q. Identification of Barkor as a mammalian autophagy-specific factor for Beclin 1 and class III phosphatidylinositol 3-kinase. Proc Natl Acad Sci USA 2008; 105: 19211-19216.

8. Yue Z, Jin S, Yang C, Levine AJ, Heintz N. Beclin 1, an autophagy gene essential for early embryonic development, is a haploinsufficient tumor suppressor. Proc Natl Acad Sci USA 2003; 100: 15077-15082.

9. Qu X, Yu J, Bhagat G, Furuya N, Hibshoosh H, Troxel A et al. Promotion of tumorigenesis by heterozygous disruption of the beclin 1 autophagy gene. J Clin Invest 2003; 112: $1809-1820$.

10. Saelens X, Festjens N, Vande Walle L, van Gurp M, van Loo G, Vandenabeele P. Toxic proteins released from mitochondria in cell death. Oncogene 2004; 23: 2861-2874.

11. Riedl SJ, Shi Y. Molecular mechanisms of caspase regulation during apoptosis. Nat Rev 2004; 5: 897-907.

12. Salvesen GS, Riedl SJ. Caspase mechanisms. Adv Exp Med Biol 2008; 615: 13-23.

13. Li J, Yuan J. Caspases in apoptosis and beyond. Oncogene 2008; 27: 6194-6206.

14. Timmer JC, Salvesen GS. Caspase substrates. Cell Death Differ 2007; 14: 66-72. 
15. Kerr JF, Wyllie AH, Currie AR. Apoptosis: a basic biological phenomenon with wide-ranging implications in tissue kinetics. Br J Cancer 1972; 26: 239-257.

16. Luthi AU, Martin SJ. The CASBAH: a searchable database of caspase substrates. Cell Death Differ 2007; 14: 641-650.

17. Galluzzi L, Vicencio JM, Kepp O, Tasdemir E, Maiuri MC, Kroemer G. To die or not to die: that is the autophagic question. Curr Mol Med 2008; 8: 78-91.

18. Levine B, Yuan J. Autophagy in cell death: an innocent convict? J Clin Invest 2005; 115: 2679-2688.

19. Yu L, Wan F, Dutta S, Welsh S, Liu Z, Freundt E et al. Autophagic programmed cell death by selective catalase degradation. Proc Natl Acad Sci USA 2006; 103: 4952-4957.

20. Scott RC, Juhasz G, Neufeld TP. Direct induction of autophagy by Atg1 inhibits cell growth and induces apoptotic cell death. Curr Biol 2007; 17: 1-11.

21. Boya P, Gonzalez-Polo RA, Casares N, Perfettini JL, Dessen P, Larochette N et al. Inhibition of macroautophagy triggers apoptosis. Mol Cell Biol 2005; 25: 1025-1040.

22. Maiuri MC, Zalckvar E, Kimchi A, Kroemer G. Self-eating and self-killing: crosstalk between autophagy and apoptosis. Nat Rev 2007; 8: 741-752.

23. Eisenberg-Lerner A, Bialik S, Simon HU, Kimchi A. Life and death partners: apoptosis, autophagy and the cross-talk between them. Cell Death Differ 2009; 16: 966-975.

24. Thorburn A. Apoptosis and autophagy: regulatory connections between two supposedly different processes. Apoptosis 2008; 13: 1-9.

25. Liang XH, Kleeman LK, Jiang HH, Gordon G, Goldman JE, Berry G et al. Protection against fatal Sindbis virus encephalitis by beclin, a novel Bcl-2-interacting protein. J Virol 1998; 72 8586-8596.

26. Maiuri MC, Le Toumelin G, Criollo A, Rain JC, Gautier F, Juin $P$ et al. Functional and physical interaction between $\mathrm{Bcl}-\mathrm{X}(\mathrm{L})$ and a $\mathrm{BH} 3-$ like domain in Beclin-1. EMBO J 2007; 26: $2527-2539$.

27. Oberstein A, Jeffrey PD, Shi Y. Crystal structure of the Bcl-XL-Beclin 1 peptide complex: Beclin 1 is a novel BH3-only protein. J Biol Chem 2007; 282: 13123-13132.

28. Pattingre S, Tassa A, Qu X, Garuti R, Liang XH, Mizushima N et al. Bcl-2 antiapoptotic proteins inhibit Beclin 1-dependent autophagy. Cell 2005; 122: 927-939.

29. He C, Klionsky DJ. Regulation mechanisms and signaling pathways of autophagy. Annu Rev Genet 2009; 43: 67-93.

30. Johnson DE. Regulation of survival pathways by IL-3 and induction of apoptosis following IL-3 withdrawal. Front Biosci 1998; 3: d313-d324.

31. Kabeya Y, Mizushima N, Ueno T, Yamamoto A, Kirisako T, Noda T et al. LC3, a mammalian homologue of yeast Apg8p, is localized in autophagosome membranes after processing. EMBO J 2000; 19: 5720-5728

32. Kabeya Y, Mizushima N, Yamamoto A, Oshitani-Okamoto S, Ohsumi Y, Yoshimori T. LC3, GABARAP and GATE16 localize to autophagosomal membrane depending on form-II formation. J Cell Sci 2004; 117 (Pt 13): 2805-2812.

33. Altman BJ, Wofford JA, Zhao Y, Coloff JL, Ferguson EC, Wieman HL et al. Autophagy provides nutrients but can lead to Chop-dependent induction of Bim to sensitize growth factor-deprived cells to apoptosis. Mol Biol Cell 2009; 20: 1180-1191.

34. Cornelis S, Bruynooghe Y, Van Loo G, Saelens X, Vandenabeele P, Beyaert R. Apoptosis of hematopoietic cells induced by growth factor withdrawal is associated with caspase-9 mediated cleavage of Raf-1. Oncogene 2005; 24: 1552-1562.

35. Verspurten J, Gevaert K, Declercq W, Vandenabeele P. SitePredicting the cleavage of proteinase substrates. Trends Biochem Sci 2009; 34: 319-323.

36. Li H, Zhu H, Xu CJ, Yuan J. Cleavage of BID by caspase 8 mediates the mitochondrial damage in the Fas pathway of apoptosis. Cell 1998; 94: 491-501.
37. Barge RM, Willemze R, Vandenabeele P, Fiers W, Beyaert R. Differential involvement of caspases in apoptosis of myeloid leukemic cells induced by chemotherapy versus growth factor withdrawal. FEBS Lett 1997; 409: 207-210.

38. Kuma A, Hatano M, Matsui M, Yamamoto A, Nakaya $H$, Yoshimori $T$ et al. The role of autophagy during the early neonatal starvation period. Nature 2004; 432 : 1032-1036.

39. Cho DH, Jo YK, Hwang JJ, Lee YM, Roh SA, Kim JC. Caspase-mediated cleavage of ATG6/Beclin-1 links apoptosis to autophagy in HeLa cells. Cancer Lett 2009; 274: 95-100.

40. Luo S, Rubinsztein DC. Apoptosis blocks Beclin 1-dependent autophagosome synthesis: an effect rescued by Bcl-xL. Cell Death Differ 2009 [Epub ahead of print].

41. Mizushima N, Yamamoto A, Hatano M, Kobayashi Y, Kabeya Y, Suzuki K et al. Dissection of autophagosome formation using Apg5-deficient mouse embryonic stem cells. J Cell Biol 2001; 152: 657-668

42. Mizushima N, Noda T, Yoshimori T, Tanaka Y, Ishii T, George MD et al. A protein conjugation system essential for autophagy. Nature 1998; 395: 395-398.

43. Yousefi S, Perozzo R, Schmid I, Ziemiecki A, Schaffner T, Scapozza L et al. Calpain-mediated cleavage of Atg5 switches autophagy to apoptosis. Nat Cell Biol 2006; 8 : 1124-1132.

44. Liang XH, Yu J, Brown K, Levine B. Beclin 1 contains a leucine-rich nuclear export signal that is required for its autophagy and tumor suppressor function. Cancer Res 2001; 61: 3443-3449.

45. Betin VM, Lane JD. Caspase cleavage of Atg4D stimulates GABARAP-L1 processing and triggers mitochondrial targeting and apoptosis. J Cell Sci 2009; 122 (Pt 14): 2554-2566.

46. Boya P, Kroemer G. Beclin 1: a BH3-only protein that fails to induce apoptosis. Oncogene 2009; 28: 2125-2127.

47. Maiuri MC, Criollo A, Tasdemir E, Vicencio JM, Tajeddine N, Hickman JA et al. BH3-only proteins and $\mathrm{BH} 3$ mimetics induce autophagy by competitively disrupting the interaction between Beclin 1 and Bcl-2/Bcl-X(L). Autophagy 2007; 3: 374-376.

48. Ciechomska IA, Goemans GC, Skepper JN, Tolkovsky AM. Bcl-2 complexed with Beclin-1 maintains full antiapoptotic function. Oncogene 2009; 28: 2128-2141.

49. Cornelis S, Bruynooghe $\mathrm{Y}$, Denecker G, Van Huffel S, Tinton S, Beyaert R. Identification and characterization of a novel cell cycle-regulated internal ribosome entry site. Mol Cell 2000; 5: 597-605

50. Vande Walle L, Van Damme P, Lamkanfi M, Saelens X, Vandekerckhove J, Gevaert K et al. Proteome-wide identification of HtrA2/Omi substrates. J Proteome Res 2007; 6 : 1006-1015.

51. Van de Craen M, Declercq W, Van den brande I, Fiers W, Vandenabeele P. The proteolytic procaspase activation network: an in vitro analysis. Cell Death Differ 1999; 6 $1117-1124$.

52. Schotte P, Van Criekinge W, Van de Craen M, Van Loo G, Desmedt M, Grooten J et al. Cathepsin B-mediated activation of the proinflammatory caspase-11. Biochem Biophys Res Commun 1998; 251: 379-387.

Cell Death and Disease is an open-access journal published by Nature Publishing Group. This article is licensed under a Creative Commons Attribution-Noncommercial-No Derivative Works 3.0 License. To view a copy of this license, visit http:// creativecommons.org/licenses/by-nc-nd/3.0/

Supplementary Information accompanies the paper on Cell Death and Disease website (http://www.nature.com/cddis) 